\title{
DISTRACTION EFFECTS OF PHONE USE DURING A CRUCIAL DRIVING MANEUVER
}

\author{
P.A. Hancock ${ }^{1,2}$ M. Lesch ${ }^{3}$ and L. Simmons ${ }^{3}$ and M. Mouloua ${ }^{1}$ \\ ${ }^{1}$ Department of Psychology, ${ }^{2}$ Institute for Simulation and Training, University of Central \\ Florida, Orlando, FL ${ }^{3}$ Liberty Mutual Research Center for Safety and Health, Hopkinton, MA
}

\begin{abstract}
Forty-two licensed drivers were tested in an experiment that required them to react to an invehicle phone at precisely the same time as they were faced with making a crucial driving decision. Using test track facilities, we extended a previous evaluation of this form to include examination of the influence of driver gender and driver age. Specifically, each driver was given task practice and then performed two blocks of twenty-four trials each, where one trial represented a circuit of the test track. Half of the trials were control conditions in which neither the stop-light was activated or the in-vehicle phone triggered. Four trials required only stopping and a further four only phone response. The remaining four trials required the driver to complete each task simultaneously. The order of presentation of specific trials was randomized. The invehicle phone response task also contained an embedded memory task that was evaluated at the end of each trial. Results confirmed previous observations of slower task response followed by increased braking and that these patterns varied by driver age and gender. Most importantly, we recorded a critical 15\% increase in non-response to the stop-light in the presence of the phone distraction task which represents stop light violations on the open road. Further, results showed that age had a much large effect on response than gender, especially on task components that required speed of response. Since driving represents a highly complex and interactive environment, it is not possible to specify a simplistic relationship between these distraction effects and outcome accident patterns. However, we can conclude that such technologies erode performance safety margin and distract drivers from their critical primary task of vehicle control. As such there is expectedly a causal relation in accident outcome that is a crucial concern for invehicle device designers and for all others seeking to ameliorate the adverse impact of vehicle accidents.
\end{abstract}

